\title{
Assessment of Early Left Ventricular Diastolic Dysfunction in Patients with Metabolic Syndrome by 2D Speckle Tracking Echocardiography Mohammed Hesham Hassan, Mohammed Saad El-Gammal, Ahmed AL-HABBAA, Eslam Mubarak Ali* \\ Department of Cardiology -Al Azhar University, Cairo, Egypt \\ *Corresponding author: Eslam Mubarak Ali; Mobile: 01140421032; Email: islam.mobarak@yahoo.com
}

\begin{abstract}
Background: Metabolic syndrome predisposes to left ventricular dysfunction and heart failure, early detection of associated subclinical cardiac changes has important diagnostic and prognostic values. 2D strain and strain rate allow detection of subtle abnormalities of global and regional left ventricular systolic and diastolic functions.

Objectives: To detect early diastolic dysfunction in the left ventricle in patients with metabolic syndrome by 2D speckle tracking echocardiography based on global longitudinal isovolumic relaxation strain rate.

Subjects and Methods: This prospective study included a total of 100 subjects divided in to 75 metabolic syndrome (MS) patients referred to Al-Azhar university hospital outpatient clinic for evaluation and treatment of hypertension and/or diabetes mellitus and 25 age and sex matched healthy volunteers as a control group. All subjects underwent conventional echocardiographic examination and assessment of diastolic dysfunction by speckle tracking.

Results: There were no statistically significant differences between MS and controls in all traditional parameters of LV systolic function. On the other hand, significant differences were observed between MS and the control group in most of the parameters of GLS and SR IVR.

Conclusion: Impairment of diastolic function detected by speckle tracking based on global longitudinal isovolumic relaxation strain rate in metabolic syndrome patients.

Keywords: Metabolic syndrome, Left ventricular diastole, Speckle tracking, Echocardiography.
\end{abstract}

\section{INTRODUCTION}

Metabolic syndrome (MS) is a condition characterized by the accumulation of multiple risk factors (insulin resistance, hyperglycemia, dyslipidemia, hypertension, visceral obesity) for cardiovascular disease in an individual with a background of obesity and/or lack of exercise ${ }^{(1)}$.

Even more with the change of the modern lifestyle and diet structure, incidence of MS increased year by year, it is greatly endangering people's health. However, it is not known whether MS is also associated with abnormal cardiac function. If MS indicates persons who have already developed abnormal left ventricular (LV) function, early recognition of MS would be important $^{(2)}$.

Left ventricle diastole occurs in order for the left ventricle (LV) to fill adequately with enough blood, at a low enough pressure, to prevent pulmonary congestion from occurring. This process is referred to as, diastolic function ${ }^{(3)}$.

Metabolic syndrome is common and it is associated with increased cardiovascular morbidity and mortality as well as with increased risk of heart failure through multiple complex metabolic reactions most prominent among which are altered insulin signaling, glycotoxcity, lipotoxicty, increase cytokine activity and intramyocyte and/or interstitial deposition of triacylglycerol plus effect of endothelial dysfunction $^{(4)}$ (Figure1).

A 2D strain echocardiographic method has been introduced that measures myocardial deformation by tracking localized acoustic markers frame by frame (speckle tracking). This method has been used for noninvasive assessment of global and regional myocardial strain in the left and the right ventricle, avoiding the angular sensitivity of tissue Doppler echocardiography (5). 


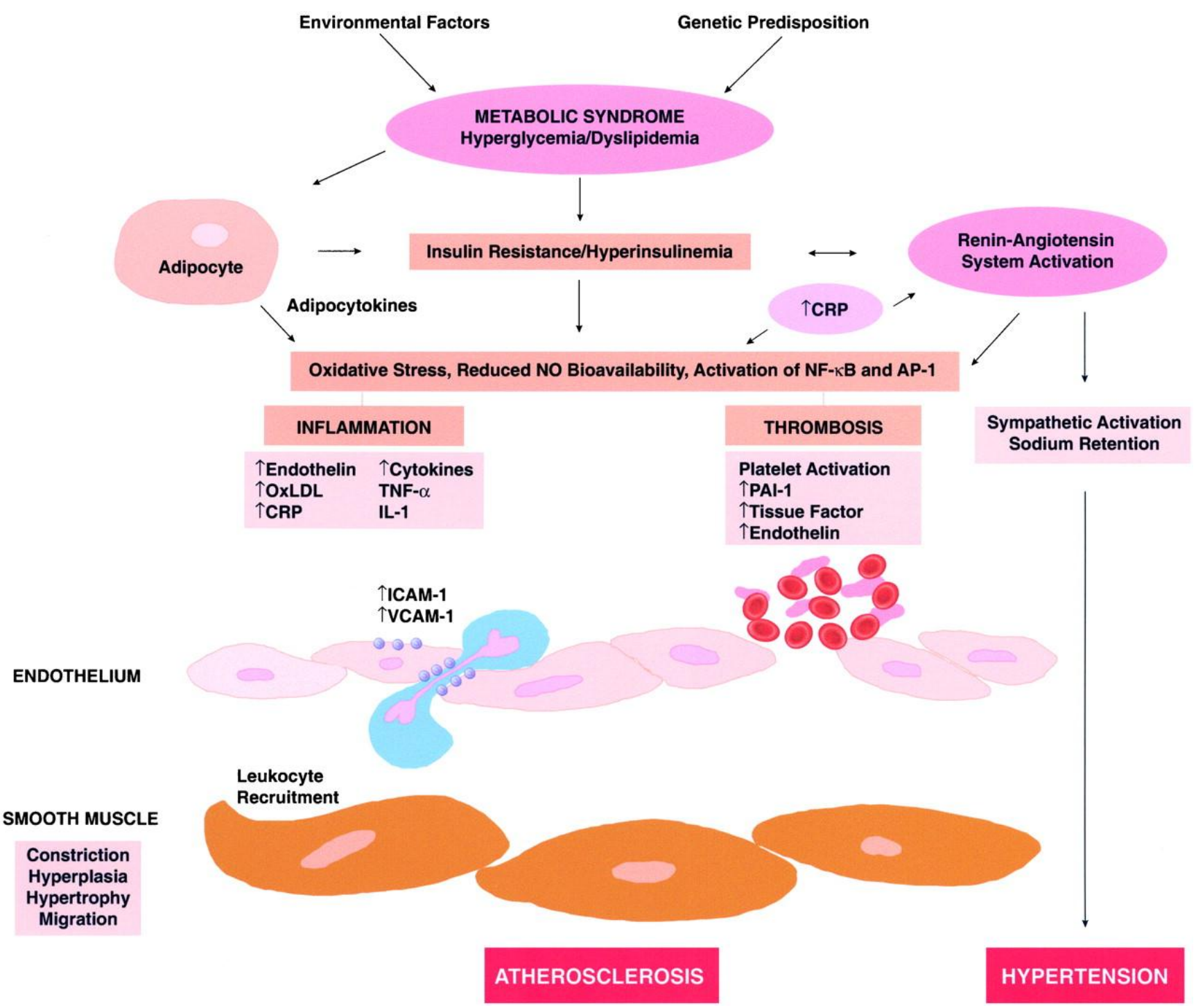

Figure (1): Pathophysiology of cardiovascular disease in metabolic syndrome.

The Aim of this Study was to detect early diastolic dysfunction in the left ventricle in patients with metabolic syndrome by $2 \mathrm{D}$ speckle tracking echocardiography based on global longitudinal isovolumic relaxation strain rate ( SR IVR ).

\section{PATIENTS AND METHODS}

This prospective study was conducted between April 2017, and May 2018 on (100) subjects divided in to (75) metabolic syndrome patients referred to Al-Azhar University Hospital Outpatient Clinic for evaluation and treatment of hypertension and/or diabetes mellitus and (25) age and sex matched healthy volunteers as a control group. Approval of the ethical committee and a written informed consent from all the subjects were obtained.

Diagnosis of MS according to International Diabetes Federation (IDF) metabolic syndrome is defined as the presence of central obesity (was determined according to the IDF criteria ${ }^{(6)}$ as the waist circumference $\geq 94 \mathrm{~cm}$ for men and $\geq 80 \mathrm{~cm}$ for women) plus any two of the following four factors:

- Low level of high-density lipoprotein (HDL) (or specific treatment for this lipid abnormality).

- High triglycerides (or specific treatment for this lipid abnormality).

- Arterial hypertension (or treatment of previously diagnosed hypertension).

- Fasting hyperglycemia (or previously diagnosed diabetes).

The study population was divided into two groups:

Group I (The patient group): Included 75 patients with characteristics metabolic syndrome (central obesity and at least two of four characteristics of MS according to the International Diabetes Federation (IDF) criteria. 
Group II (Control Group): Included 25 healthy age and sex matched volunteers free from cardiovascular risk factors.

Exclusion criteria: It included patients with ejection fraction $<55 \%$ or with symptoms or sign of heart failure, patients with known coronary artery disease, patients with significant valvular disease, patients with prosthetic mitral valve and patients with atrial fibrillation or other rhythm disturbances.

\section{The following data were collected:}

A. Complete and detailed medical History: With attention to Hypertension, DM and family history of premature coronary artery disease.

B. Full clinical examination including waist circumference, body surface area (7), heart rate, rhythm, systolic, diastolic blood pressure, heart, and chest auscultation.

c. Conventional echocardiographic Doppler study and 2D speckle tracking were performed using Philips iE33 X Matrix ultrasound machine using X5-
1 matrix array transducers (Philips Medical Systems, Andover, USA).

\section{Systolic function assessment}

a. Ejection fraction (EF\%) and fractional shortening (FS\%) were performed to evaluate LV systolic function by 2D echo.

b. LVEDV and LVESV were calculated from the apical 2-and 4-chamber views using a modified biplane Simpson's method.

c. Ejection fraction (EF\%) was calculated as percentage changes of volumes of the left ventricle in diastole and systole. The LV ejection fraction (EF\%) was automatically calculated as follows:

$(\mathrm{EF} \%)=(\mathrm{EDV}-\mathrm{ESV}) / \mathrm{EDV} \times 100^{(8)}$.

\section{Diastolic function assessment}

LV diastolic function was evaluated using the four recommended variables for identifying diastolic dysfunction ${ }^{(9)}$ (Figure 2).

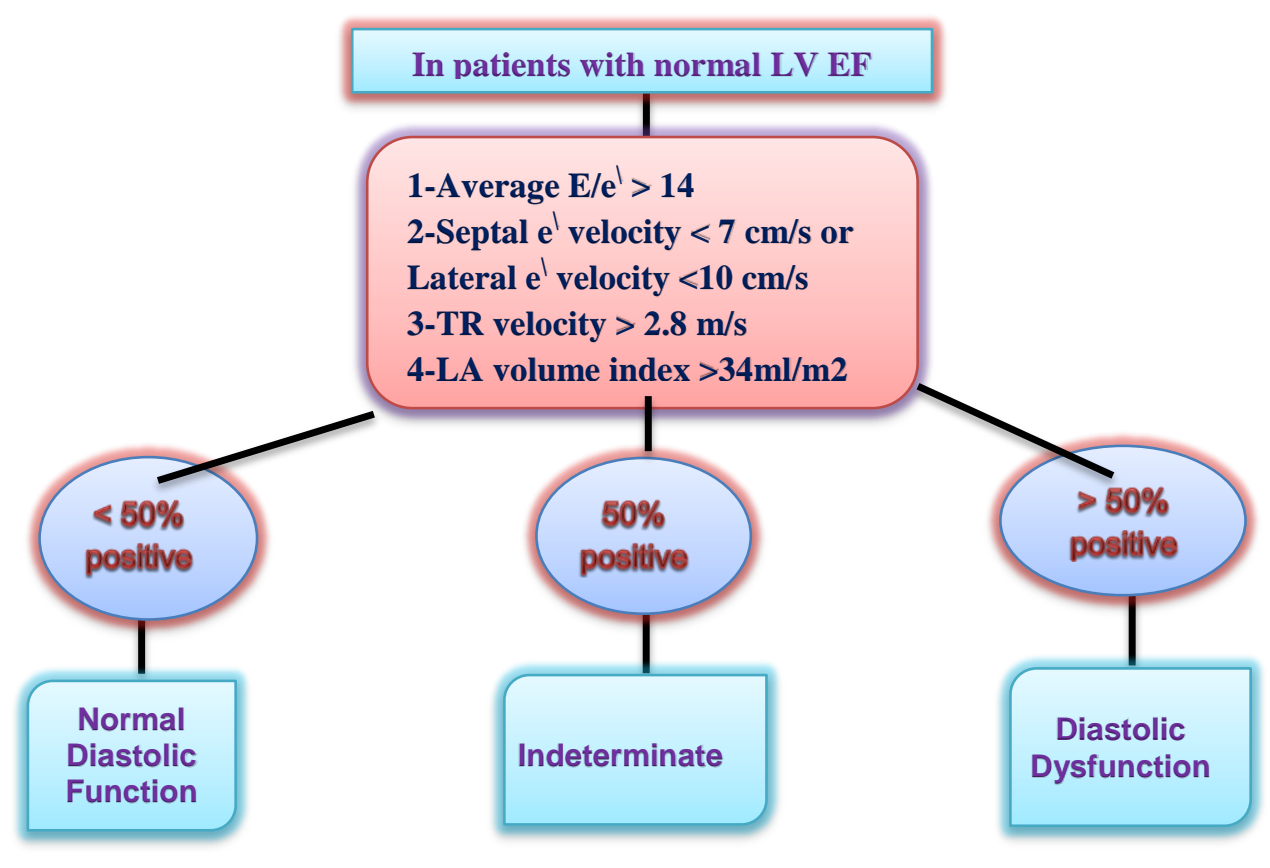

FIGURE (2).Algorithm for diagnosis of LV diastolic dysfunction in subjects with normal LVEF.

Two-dimensional speckle tracking echocardiography (2D STE): Longitudinal systolic strain and diastolc isovolumic relaxation strain rate was assessed in the $6 \mathrm{LV}$ walls and the software algorithm automatically segmented the LV into 17 equidistant segments and each segment was analyzed separately. Global LV diastolic SRIVR obtained from averaging the peak values of $17 \mathrm{LV}$ segments were calculated and used for comparisons between control and metabolic syndrome groups (Figure 3).

All variables in this study represent the mean value of measurements taken in 3 consecutive cardiac cycles. 


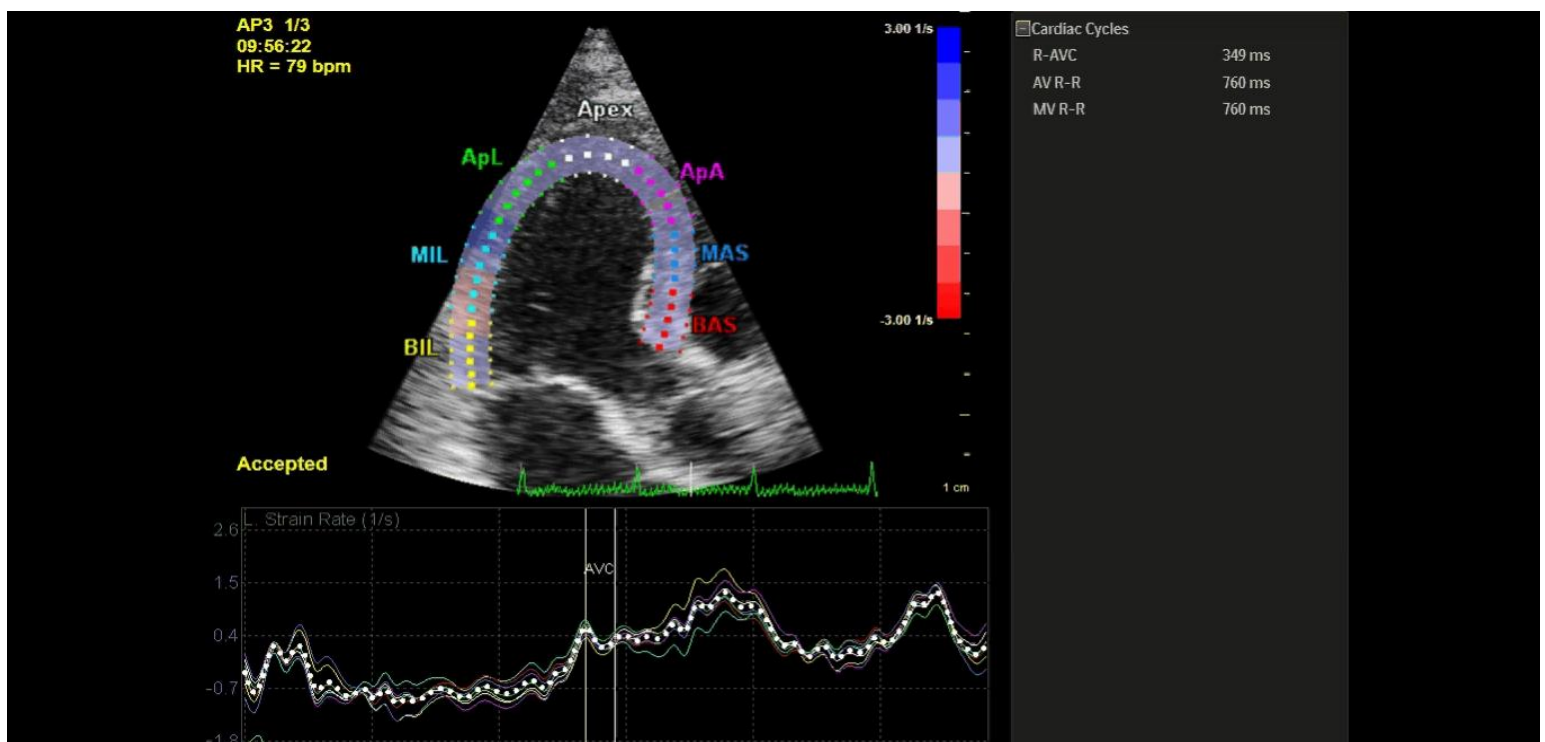

Figure(3). 2D STE measurements of longitudinal isovolumic relaxation diastolic SR (SRIVR) in the apical 3ch view in a control subject after Aortic valve closure(AVC) and before Mitral valve opening (MVO).

\section{Statistical analysis}

Data were fed to the computer and analyzed using IBM SPSS software package version 20.0. (Armonk, NY: IBM Corp). The Kolmogorov-Smirnov test was used to verify the normality of distribution Quantitative data were described using range (minimum and maximum), mean, standard deviation and median. Significance of the obtained results was judged at the $5 \%$ level.
The used tests were F-test (ANOVA) for normally distributed quantitative variables to compare between more than two groups and Post Hoc test (Tukey) (LSD) for pair wise comparisons.

\section{RESULTS}

Regarding Demographic and Clinical data: In the present study, there were no significant differences between the two groups as regards age and sex (Table $1 \& 2)$.

Table (1): Comparison between two groups according to Age

\begin{tabular}{|c|c|c|c|c|}
\hline Variables & $\begin{array}{c}\text { Group I } \\
\text { MS }\end{array}$ & $\begin{array}{c}\text { Group II } \\
\text { Control }\end{array}$ & \multirow{2}{*}{ T test } & \multirow{2}{*}{ P - value } \\
\cline { 2 - 3 } & mean \pm SD) & $\begin{array}{c}\text { (mean } \pm \\
\text { SD) }\end{array}$ & & \\
\hline Age(year) & $\begin{array}{c}34.72 \pm \\
4.05\end{array}$ & $\begin{array}{c}32.8 \pm \\
3.97\end{array}$ & 0.6 & 0.537 \\
\hline
\end{tabular}

Table (2): Comparison between the study groups regarding gender

\begin{tabular}{|l|c|l|l|l|l|c|}
\hline \multicolumn{2}{|c|}{ Sex } & \multicolumn{3}{c|}{ Groups } & \multicolumn{2}{c|}{ Chi-square } \\
\cline { 3 - 6 } \multicolumn{2}{|c|}{} & $\begin{array}{l}\text { Group I } \\
\text { (MS) } \\
\mathrm{N}=75\end{array}$ & $\begin{array}{l}\text { Group II } \\
\text { (control) } \\
\mathrm{N}=25\end{array}$ & $\begin{array}{l}\text { Total } \\
\mathrm{N}=100\end{array}$ & X2 & P-value \\
\hline Female & $\mathrm{N}(\%)$ & $48(64 \%)$ & $14(56 \%)$ & $62(62 \%)$ & \multirow{2}{*}{1.415} & 0.268 \\
\hline Male & $\mathrm{N}(\%)$ & $27(36 \%)$ & $11(44 \%)$ & $38(38 \%)$ & \\
\hline
\end{tabular}




\section{Conventional echocardiography}

LA dimension, LVEDD, LV wall thickness and LV mass were significantly higher in the metabolic syndrome group than the controls, while there were no differences regarding FS, EF and LV mass index.

Furthermore, the diastolic function was more impaired in metabolic syndrome patients compared to the controls as evidenced by increasing $\mathrm{E} / \mathrm{E}^{\prime}$ Ratio, LA volume index, TR jet velocity and decreasing $\mathrm{E}^{\prime}$ septal and $\mathrm{E}^{\prime}$ Lateral in the metabolic syndrome group (Table 3\& 4 ).

Table (3): Comparison between metabolic syndrome group and control group regarding the Recommendations for the Evaluation of Left Ventricular Diastolic function.

\begin{tabular}{|c|c|c|c|}
\hline Variables & $\begin{array}{c}\text { Group I } \\
\text { MS }\end{array}$ & $\begin{array}{l}\text { Group II } \\
\text { Control }\end{array}$ & P-value \\
\hline E $^{\prime}$ septal (Mean \pm SD) & $5.52 \pm 0.96$ & $9.13 \pm 0.88$ & $<0.001^{*}$ \\
\hline$E^{\prime}$ lateral (Mean \pm SD) & $9.64 \pm 0.12$ & $13.01 \pm 1.07$ & $0.047^{*}$ \\
\hline E/E' Ratio (Mean \pm SD) & $10.8 \pm 1.9$ & $7.1 \pm 1.6$ & $0.002^{*}$ \\
\hline LA volume index mL/m2 (Mean \pm SD) & $27.66 \pm 3.96$ & $21.72 \pm 2.80$ & $0.004^{*}$ \\
\hline TR jet velocity >2.8 m/sec N(\%) & $19(25.3 \%)$ & $0(0 \%)$ & $0.001^{*}$ \\
\hline
\end{tabular}

Table (4): Comparison between normal and metabolic syndrome patients regarding the conventional echo parameters.

\begin{tabular}{|c|c|c|c|}
\hline \multirow{2}{*}{$\begin{array}{l}\text { Conventional } \\
\text { Echocardiography }\end{array}$} & $\begin{array}{c}\text { Group I } \\
\text { MS }\end{array}$ & $\begin{array}{c}\text { Group II } \\
\text { Control } \\
\end{array}$ & \multirow[b]{2}{*}{ P-value } \\
\hline & Mean \pm SD & Mean \pm SD & \\
\hline $\mathrm{AO}(\mathrm{cm})$ & $3.12 \pm 0.28$ & $2.93 \pm 0.41$ & 0.088 \\
\hline $\mathrm{LA}(\mathrm{cm})$ & $3.83 \pm 0.36$ & $3.18 \pm 0.25$ & $0.01^{*}$ \\
\hline IVS, mm & $8.2 \pm 1.4$ & $7.5 \pm 0.7$ & $0.02 *$ \\
\hline LVEDD, mm & $\begin{array}{c}50.58 \pm \\
3.20\end{array}$ & $\begin{array}{l}46.69 \pm \\
2.94\end{array}$ & $0.04 *$ \\
\hline LVESD, mm & $\begin{array}{c}30.34 \pm \\
2.50\end{array}$ & $\begin{array}{l}28.85 \pm \\
2.68\end{array}$ & 0.285 \\
\hline LVPWD, mm & $8.2 \pm 1.2$ & $7.3 \pm 0.5$ & $0.012 *$ \\
\hline $\mathrm{EF} \%$ & $\begin{array}{c}65.74 \pm \\
3.71\end{array}$ & $\begin{array}{l}65.89 \pm \\
4.03\end{array}$ & 0.809 \\
\hline FS \% & $\begin{array}{c}36.94 \pm \\
2.89\end{array}$ & $\begin{array}{c}37.05 \pm \\
3.48\end{array}$ & 0.709 \\
\hline LV mass (gram) & $\begin{array}{c}148.96 \pm \\
15.01\end{array}$ & $\begin{array}{c}127.6 \pm \\
15.86\end{array}$ & $0.044^{*}$ \\
\hline $\mathrm{LV}$, mass index $(\mathrm{g} / \mathrm{m} 2)$ & $\begin{array}{c}72.65 \pm \\
6.38\end{array}$ & $\begin{array}{c}70.82 \pm \\
10.24\end{array}$ & 0.611 \\
\hline $\mathrm{E}, \mathrm{cm} / \mathrm{s}$ & $68.5 \pm 15$ & $88 \pm 13$ & $<0.001^{*}$ \\
\hline $\mathrm{A}, \mathrm{cm} / \mathrm{s}$ & $88.2 \pm 16$ & $61.7 \pm 10.5$ & $<0.001^{*}$ \\
\hline $\mathrm{E} / \mathrm{A}$ & $0.81 \pm 0.21$ & $1.47 \pm 0.23$ & $<0.001^{*}$ \\
\hline
\end{tabular}

IVS: interventricular septum ; LA : left atrium ; AO: Aorta ; PWD ; posterior wall diamension ; End SD: End systolic diameter; End DD: End diastolic diameter; EF: Ejection fraction; FS : fraction shortening ; E: E velocity; A: A velocity; MS: Metabolic syndrome.

Twenty of 75 metabolic syndrome subjects (26.6\%) did not meet criteria for diastolic dysfunction (normal diastolic function), 38(50.8\%) subjects had Grade 1 diastolic dysfunction, 13 subjects (17.3\%) had Grade 2 diastolic dysfunction and 4 (5.3\%) had Grade 3 diastolic dysfunction (Figure 4). 


\section{Percent}

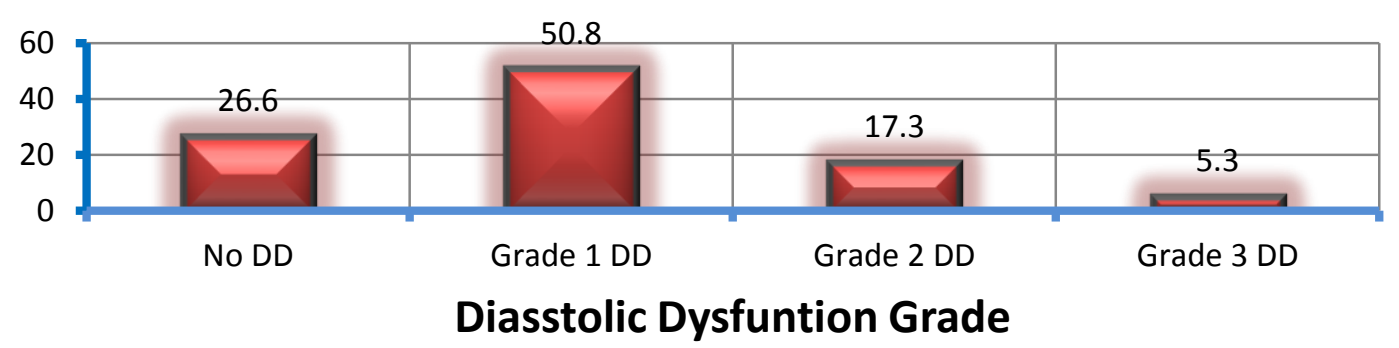

Figure (4); Diastolic dysfunction grade among metabolic syndrome group.

\section{D-speckle tracking imaging}

\section{A-Peak systolic strain \%}

Comparing the two groups as regard global longitudinal peak systolic strain was significantly lower in patients with metabolic syndrome compared with normal population $(\mathrm{P}<0.001 *)$ (Table 5\& Figure 5).

\section{B- Strain Rate}

Comparing the two groups as regard longitudinal isovolumic relaxation strain rate (SRIVR) was significantly lower in patients with metabolic syndrome compared with normal population $\left(\mathrm{P}<0.001^{*}\right)$ (Table 6 \& figure 6).

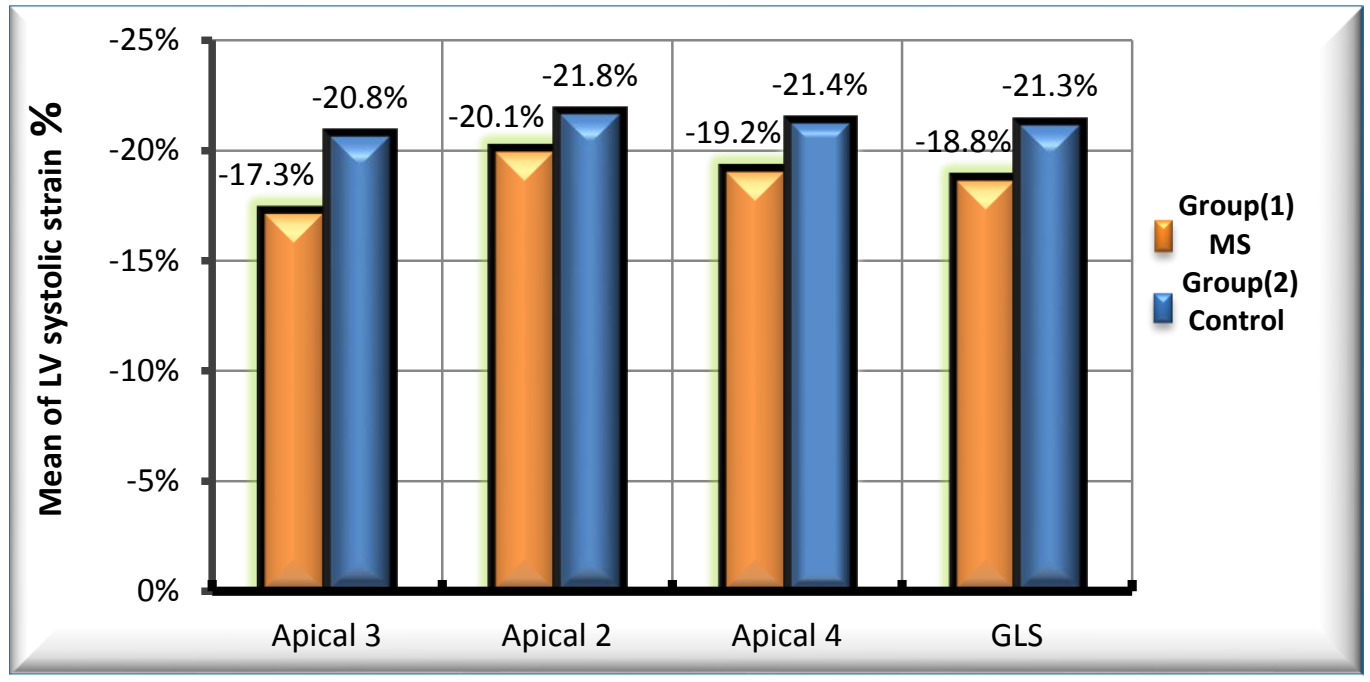

Figure (5).Comparison between the two studied groups according to Apical (2,3 and 4 views) and global longitudinal left ventricle systolic strain \%.

Table 5. The mean value of global longitudinal left ventricular (LV) strain in individuals with metabolic syndrome and control group

\begin{tabular}{|l|c|c|c|}
\hline \multirow{2}{*}{ Variables } & $\begin{array}{c}\text { Group I } \\
\text { MS }\end{array}$ & $\begin{array}{c}\text { Group II } \\
\text { Control }\end{array}$ & \multirow{2}{*}{ P-value } \\
\cline { 2 - 3 } & Mean \pm SD & Mean \pm SD & \\
\hline Longitudinal strain Apical 3 & $-17.3 \pm 3.6$ & $-20.8 \pm 3.7$ & $<\mathbf{0 . 0 0 1 *}$ \\
\hline Longitudinal strain Apical 4 & $-19.2 \pm 2.6$ & $-21.4 \pm 2.7$ & $\mathbf{0 . 0 3 0}$ \\
\hline Longitudinal strain Apical 2 & $-20.1 \pm 2.5$ & $-21.8 \pm 2.8$ & $\mathbf{0 . 1}$ \\
\hline $\begin{array}{l}\text { Global Longitudinal strain } \\
\text { (GLS) }\end{array}$ & $-18.86 \pm 2.2$ & $-21.33 \pm 2.1$ & $<\mathbf{0 . 0 0 1 *}$ \\
\hline
\end{tabular}




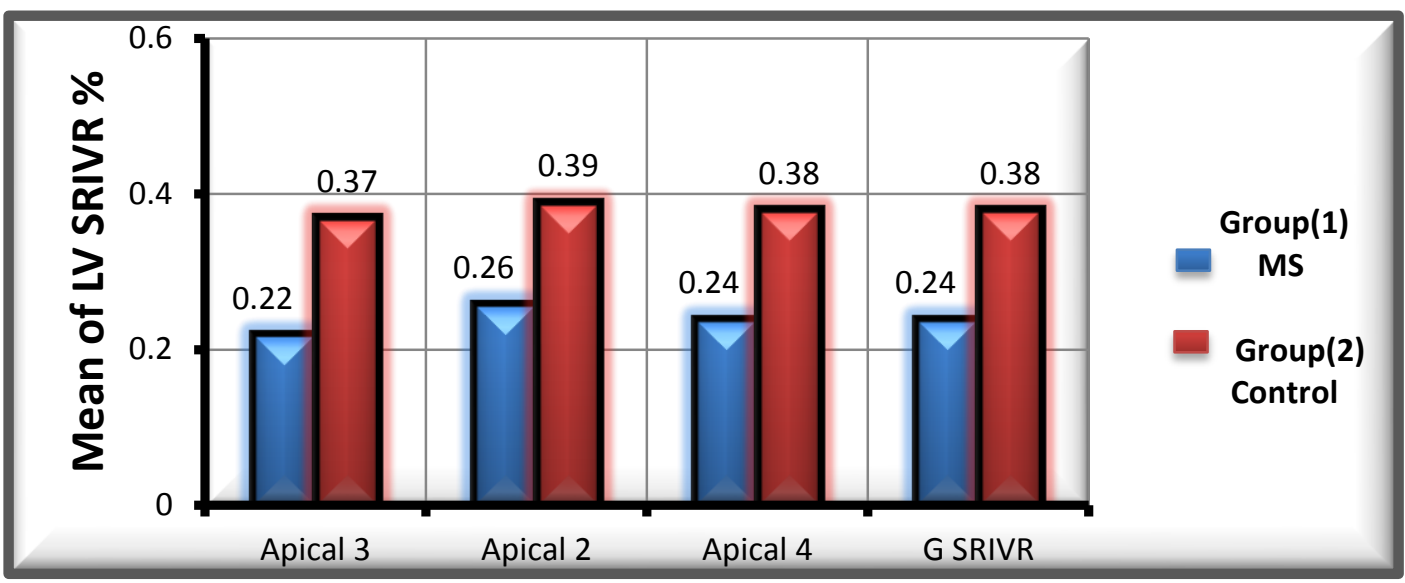

Figure (6). Comparison between two groups as regard Apical (2, 3 and 4 views) and global longitudinal Isovolumic relaxation strain rate (SRIVR) .

Table (6). Comparison between two groups as regard longitudinal Isovolumic relaxation strain rate (SRIVR).

\begin{tabular}{|l|r|r|c|}
\hline \multirow{2}{*}{ Variables } & Group I (MS) & Group II (Control) & \multirow{2}{*}{ P-value } \\
\cline { 2 - 3 } & Mean \pm SD & Mean \pm SD & $<0.001^{*}$ \\
\hline Longitudinal Apical (3) SRIVR $\left(\mathrm{s}^{-1}\right)$ & $0.22 \pm 0.08$ & $0.37 \pm 0.11$ & $<0.00 .12$ \\
\hline Longitudinal Apical (4) SRIVR $\left(\mathrm{s}^{-1}\right)$ & $0.24 \pm 0.0$ & $0.38 \pm 0.12$ & $0.008^{*}$ \\
\hline Longitudinal Apical (2) SRIVR $\left(\mathrm{s}^{-1}\right)$ & $0.26 \pm 0.12$ & $0.39 \pm 0.09$ & $0.005^{*}$ \\
\hline Global Longitudinal SRIVR $\left(\mathrm{s}^{-1}\right)$ & $0.24 \pm 0.15$ & $0.38 \pm 0.09$ & $<0.05^{*}$ \\
\hline
\end{tabular}

\section{DISCUSSION}

Metabolic syndrome is described by a combination of underlying risk factors such as central obesity, glucose intolerance, low level of high-density lipoproteins $(\boldsymbol{H D L})$, high triglyceride (TG) level, and hypertension. that when occurring together culminate in adverse outcomes, including cardiovascular disease $(\boldsymbol{C V D})^{(1)}$.

Strain $(\varepsilon)$ is a measure of tissue deformation. As the ventricle contracts, muscle shortens in longitudinal and circumferential dimensions (a negative strain) and thickens or lengthens in radial direction (a positive strain). Strain rate (SR) is the local rate of deformation that measures the time course of deformation or strain per unit time ${ }^{(10)}$.

In contrast to TDI, speckle tracking echocardiography is an angle-independent technique that allows an accurate assessment of segmental myocardial deformation by grey-scale based imaging analysis frame by frame. Moreover, the lack of angle-dependency is of great advantage as myocardial strain $(\varepsilon)$ could be tracked in two dimensional echo imaging along the direction of the wall and not along the ultrasound beam ${ }^{(11)}$.

The present study was designed to evaluate left ventricle diastolic functions in metabolic syndrome patients compared to control subjects using 2Dspeckle tracking echocardiography based on global longitudinal isovolumic relaxation strain rate. The present study, showed that there was statistical significant difference between the two groups ( I \& II ) as regard weight, body mass index

(BMI), waist circumference, hip circumference ( $\mathrm{p}$ value $<0.001)$. Also, there was no statistical significant difference between the two groups (I \& II ) as regard body surface area ( $p$-value $>0.05$ ).

Also, there was statistical significant difference between the two groups ( I \& II ) as regard fasting plasma glucose , HDL-cholesterol and Fasting Triglycerides ( P-Value $<0.001$ ).

These findings were similar to Qin Wang and his colleagues ${ }^{(12)}$ who studied early detection of regional and global left ventricular myocardial function, that shows no significant difference was observed among the groups regarding age, sex, heart rate. There were significant differences in W. circum., body mass index (BMI), BP, FPG, cholesterol, low density lipoprotein and triglycerides between MS. and the control groups.

In our study regarding diastolic dysfunction grade among metabolic syndrome group showed that first grade of diastolic dysfunction (impaired relaxation) was the most common disorder (Figure 4). Also we found that regarding number of characteristics of metabolic syndrome to the degree of diastolic dysfunction, we found the existence of relationship between the intensity of metabolic syndrome (rated by the number of coexisting characteristics of MS) and left ventricular diastolic dysfunction as a parameter of subclinical organ damage (figure 7). 


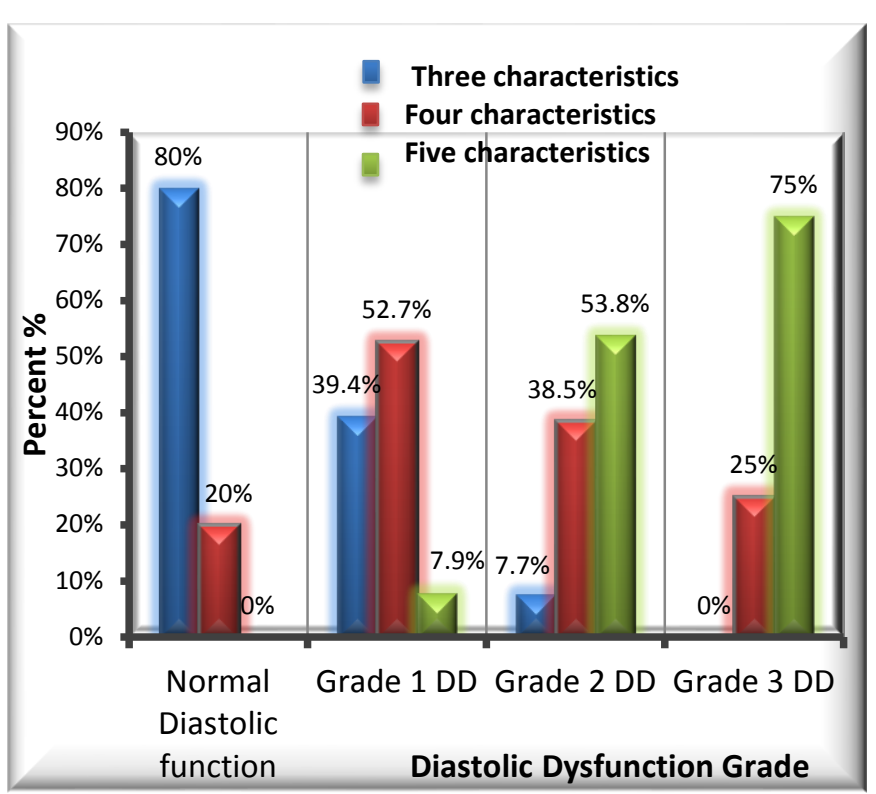

Figure (7). Characteristics of metabolic syndrome according to the degree of diastolic dysfunction.

In addition, the positive correlation was found between the grade of diastolic dysfunction and central obesity $\left(p<0.0001^{*}\right)$, arterial hypertension $\left(p<0.0001^{*}\right)$, impaired glucose tolerance/diabetes $(\mathrm{p}<0.0063)$ and high level of triglycerides $(p<0.0262)$ as the separate criteria. No statistically significant correlation was found between the grade of diastolic dysfunction and low level of HDL cholesterol $(\mathrm{p}=0.3325)$. These observations were similar to Davor and his colleagues ${ }^{(13)}$ who studied left ventricular diastolic dysfunction in 72 patients (29 male and 43 female) patient with MS. There was a positive correlation between the number of characteristics of metabolic syndrome and the diastolic dysfunction grade $(\mathrm{p}<0.0001)$. The positive correlation was found between the grade of diastolic dysfunction and the waist circumference $(\mathrm{p}<0.0001)$ arterial hypertension $(\mathrm{p}<0.001)$, impared glucose tolerance/diabetes $(\mathrm{P}=0.0063)$, and hypertriglyceridemia $(\mathrm{p}=0.0262)$. A low level of high-density lipoprotein did not show a statistically significant correlation.

In our study, upon assessment of LV diastolic function by conventional and Doppler Echocardiography, We found that MS. was associated with preclinical LV diastolic dysfunction as reflected by higher LA volume index $\mathrm{mL} / \mathrm{m} 2$, lower E/A ratio, TR jet velocity $>2.8 \mathrm{~m} / \mathrm{sec}$, reduced $\mathrm{e}^{\prime}$ septal and lateral wave and increased average $\mathrm{E} / \mathrm{e}$ ratio in comparison to control group.

These findings are compatible with the study of Nir et al. ${ }^{(14)}$ who studied 90 participants with MS and without cardiovascular disease and 26 controls for preclinical LV diastolic dysfunction, shows that MS was associated with higher left atrial (LA) volume index d, higher LV mass, lower E/A ratio, and lower mean $\mathrm{e}^{\prime}(\mathrm{p}<0.001$ for all $)$.

In our study, upon assessment of LV diastolic function by 2D STE, it was confirmed that, impaired global longitudinal isovolumic relaxation strain rate in patients with metabolic syndrome with normal ejection fraction (EF) compared to control group with normal ejection fraction (EF) $(0.24 \pm$ $0.15\left(\mathrm{~s}^{-1}\right)$ vs. $\left.0.38 \pm 0.09\left(\mathrm{~s}^{-1}\right), \mathrm{P}<0.05\right)$.

These findings were compatible with the study of Qin Wang et al. ${ }^{(12)}$ who studied 39 metabolic syndrome subjects with normal ejection fraction and 39 control subjects of similar age and found that; significant differences were observed between MS and the control group in most of the parameters of Strain, SR $\left(\mathrm{s}^{-1}\right)$, SRIVR $\left(\mathrm{s}^{-1}\right)$ in LV function and shows that assessment of myocardial function using SRI could be more accurate in MS patient evaluation than conventional echocardiography alone.

These findings were similar to Hui-ping and his colleagues (15) who studied Impaired left ventricular systolic and diastolic function in patients with metabolic syndrome as assessed by strain and strain rate imaging in (200) patients with metabolic syndrome and (197) control subjects of similar age and found that; the mean systolic strain, SR-LVs and SR-LV ivr , were significantly decreased in MS. when compared with control subjects (all $\mathrm{P}<0.001$ ). LV systolic and diastolic functions were impaired in patients with metabolic syndrome even if they have normal LVEF. Strain and SR imaging would be a sensitive and feasible method to detect subclinical abnormalities in those populations.

In our study, Upon assessment of LV systolic function by conventional Echocardiography, it was confirmed by this study that, conventional echocardiography was not able to detect early abnormalities in LV systolic function as there was no significant difference between metabolic syndrome group and controls regarding LV ejection fraction (EF) and fractional shortening (FS).

These findings were similar to Qin Wang and his colleagues ${ }^{(12)}$ who studied early detection of regional and global left ventricular myocardial function in (39) patients with metabolic syndrome and (39) control subjects of similar age and found that; There was no statistically significant difference between the two groups as regard LV ejection fraction (EF) and fractional shortening (FS).

In our study, Upon assessment of LV systolic function by 2D STE appears to be more sensitive than conventional echocardiography in identifying a reduction of intrinsic myocardial contractility, that shows impaired global longitudinal strain in 
patients with metabolic syndrome with normal ejection fraction (EF) compared to control group with normal ejection fraction (EF) $(-18.86 \pm 2.2 \%$ vs. $-21.33 \pm 3.1 \%, \mathrm{P}<0.001)$.

These findings were compatible with the study of Alireza et al. ${ }^{(16)}$ who studied 36 metabolic syndrome subjects with normal ejection fraction and 57 control subjects of similar age and found that; EF and fractional shortening were similar between both groups. Global longitudinal strain was significantly lower in patients with metabolic syndrome compared with normal population $(-18.41 \pm 2.40 \%$ vs. $-21.2 \pm 2.41 \%, \mathrm{P}<0.001)$.

\section{CONCLUSION}

In conclusion, the current study showed that, metabolic syndrome group have an associated abnormal left ventricle diastolic performance based on impaired global longitudinal isovolumic relaxation strain rate. Also, associated with abnormal left ventricle systolic performance based on impaired global longitudinal systolic strain despite normal LV EF\% in this group.

So, patients with metabolic syndrome should be receive aggressive therapy to avoid occurrence of heart failure in the future.

\section{STUDY LIMITATIONS}

- Our study included subjects with different onset, severity, and treatment modalities of metabolic syndrome components. The small number of the study participants may have influenced our results.

- Rapid events during the cardiac cycle (e.g. isovolumic phases) may disappear altogether, and peak strain rate (SR) may be reduced due to under-sampling, especially in isovolumic phases and in early diastole. Higher frame rates could reduce the under-sampling problem, although this will result in a reduction of spatial resolution and consequently, less optimal ROI tracking.

- Strain, Strain rate (SR) and conventional echo Doppler measurements were not measured at the same cardiac cycle; but meticulous care was done to take measurements at cycles with nearly equal R-R interval.

- All subjects in our study did not have any signs or symptoms of angina and had normal findings on electrocardiogram and on 2-D Echocardiography, we could not completely exclude asymptomatic coronary artery disease.

\section{REFERENCES}

1. Harris MF (2013): The metabolic syndrome. Aust Fam Physician, 42: 524-527.
2. Briand M, Lemieux I, Dumesnil JG et al. (2006): Metabolic syndrome negatively influences disease progression and prognosis in aortic stenosis. J Am Coll Cardiol., 47(11):2229-36.

3. Chung C , Shmuylovich L \& Kovács S (2015): What global diastolic function is, what it is not, and how to measure it. Am. J. Physiol. Heart Circ. Physiol., 309:392-406.

4. Alessi MC, Juhan I (2008): Metabolic syndrome, haemostasis and thrombosis. Thromb Haemost., 99(6):995 1000.

5. Blessberger $H$ and Binder $\mathbf{T}$ (2010): Non-invasive imaging: two dimensional speckle tracking echocardiography basic principles. Heart, 96:716-722.

6. Alberti KG, Zimmet P, Shaw J (2006): Metabolic syndrome-a new world-wide definition. A Consensus Statement from the International Diabetes Federation. Diabetic Med., 23(5):469-80.

7. Du Bois D, Du Bois EF (Jun 1916): A formula to estimate the approximate surface area if height and weight be known". Archives of Internal Medicine, 17 (6): 863-71.

8. Bulwer JW, Lang RM, Bierig M, Devereux RB, Melamed R (2009): Assessment of Left Ventricular Function by Intensivists Using Hand-Held Echocardiography. J Card Fail., 15:782-789.

9. Nagueh SF, Appleton CP, Gillebert TC, Marino PN, Oh JK, Smiseth OA et al. (2016): Recommendations for the evaluation of left ventricular diastolic function by echocardiography. J Am Soc Echocardiogr., 29:277-314.

10. Yingchoncharoen $\mathrm{T}$, Agarwal $\mathrm{S}$, Popović $\mathrm{ZB}$ et al. (2013): Normal ranges of left ventricular strain: a metaanalysis. J Am Soc Echocardiogr., 26 (2): 185-91.

11. Bhella PS, Pacini EL, Prasad A, Hastings JL, Adams B, Thomas JD et al. (2011): Echocardiographic indices do not reliably track changes in left-sided filling pressure in healthy subjects or patients with heart failure with preserved ejection fraction. Circ. Cardiovasc Imag ., 4: $482-489$.

12. Qin Wang, Qi-Wei Sun, Dan Wu, Ming-Wu Yang, Rong-Juan Li et al. (2015): Early Detection of Regional and Global Left Ventricular Myocardial Function Using Strain and Strain-rate Imaging in Patients with Metabolic Syndrome. Chin Med J (Engl)., 128(2):226-32.

13. Davor Penjaskovic, Dejan sakac, Jovanka Dejanovic, Radovan Zec et al. (2012): Left ventricular diastolic dysfunction in patients with metabolic syndrome. Med Pregl., 65(2):18-22.

14. Nir A, Deepa M, Deirdre M, Juliana S, Jason $R$ et al. (2016): Metabolic Syndrome is Associated With Diastolic Dysfunction Independent of Left Ventricular Hypertrophy. Circulation, 128:A11573.

15. Hui-ping Gong, Hong-wei Tan, Ning-ning Fang et al. (2009): Impaired left ventricular systolic and diastolic function in patients with metabolic syndrome as assessed by strain and strain rate imaging. Diabetes Res. Clin Pract., 83(3):300-7.

16. Alireza Moaref, Majid Faraji, Maryam Tahamtan (2015): Subclinical left ventricular systolic dysfunction in patients with metabolic syndrome: A case-control study using two-dimensional speckle tracking echocardiography. ARYA Atheroscler., 99:115-10. 